\title{
American Journal of Applied Chemistry
}

\section{5; 3(3): 134-138}

Published online May 18, 2015 (http://www.sciencepublishinggroup.com/j/ajac) doi: 10.11648/j.ajac.20150303.16

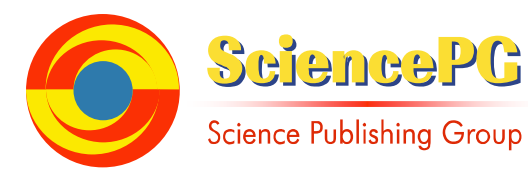

\section{Screening Nigerian Kaolin for Use as Potential Sources of Geopolymer Materials}

\author{
Olawale, Margaret Damilola ${ }^{1,2}$, Ogundiran, Mary B. ${ }^{1}$ \\ ${ }^{1}$ Analytical/Environmental Unit, Department of Chemistry, University of Ibadan, Ibadan, Nigeria \\ ${ }^{2}$ Department of Physical and Chemical Sciences, Elizade University, Ilara-mokin, Ondo State, Nigeria
}

Email address:

mag4john@yahoo.com (M. D. Olawale), olawale.margaret@elizadeuniversity.edu.ng (M. D. Olawale), mbogundiran@yahoo.com (M. B. Ogundiran)

\section{To cite this article:}

Olawale, Margaret Damilola, Ogundiran, Mary B.. Screening Nigerian Kaolin for Use as Potential Sources of Geopolymer Materials. American Journal of Applied Chemistry. Vol. 3, No. 3, 2015, pp. 134-138. doi: 10.11648/j.ajac.20150303.16

\begin{abstract}
The search for alternative low cost and environment friendly binder has led to the screening of Nigerian kaolinite clay for the production of geopolymer binders. Three batches of geopolymer binders were synthesised using five Nigerian kaolinite clays, locally synthesised sodium silicate and $\mathrm{NaOH}$. The clays were Ikere Ekiti (Ekiti State) kaolin, Ikare (Ondo State) kaolin, fired clay (Ozubulu, Imo state), Enugu (Enugu state) kaolin, and laterite (Lagos State).The first batch was activated with sodium silicate and water in ratio one to one. The second batch was activated with sodium silicate and water in ratio one to half and the last batch was activated with sodium silicate and sodium hydroxide in ratio one to one. Six mixes for each sample were prepared for the first and second batches of geopolymer binder. They were cured at room temperature for seven days, $75^{\circ} \mathrm{C}$, $150^{\circ} \mathrm{C}$ and $500^{\circ} \mathrm{C}$. The last batch of the geopolymer binder was cured at $150^{\circ} \mathrm{C}$. The result of the research confirmed that compressive strength of kaolinite clay based geopolymer binder increased with increase in curing time from 7 days room temperature to $500^{\circ} \mathrm{C}$. All geopolymers activated with both sodium silicate and sodium hydroxide demonstrated sharp increase in their compressive strength values when compare with geopolymer activated with sodium silicate and water. Comparing the geopolymers activated with both sodium silicate and $\mathrm{NaOH}$ in ratio one to one with ASTM Specification Standard, Ikare sample satisfied ASTM Specification Standard C62 and C90. Similarly, Ikere Ekiti geopolymer satisfied ASTM Specification Standard C62, C90, C216, and C902. Water absorption test performed showed that all the samples have good water absorption capacity at different conditions when compared with ASTM Specification Standard for water absorption, except Enugu kaolin and Ozubulu clay which did not satisfied the ASTM requirements at room temperature and at $75^{\circ} \mathrm{C}$. Nigerian kaolinite clays have potentials to be used as geopolymer binders which may be applied in construction.
\end{abstract}

Keywords: Geopolymer, Kaolin, Compressive Strength, Water Absorption

\section{Introduction}

For many years, incidents of building collapse have been wreaking havoc on hapless Nigerians. Many people have been sent to their untimely graves, other, though survived such catastrophes, are maimed for life just as properties worth billions of naira have been lost. The cause of many of the building that collapse has been attributed to use of inferior materials, poor concrete mixes and high cost of Portland cement[1].

The Cement Manufacturers' Association of Nigeria (CMAN) commented that Portland cement production has increased in 2002 from 2 million tones to about 17.5 millions tones annually. CMAN emphasised that the increment in cement price is due to high cost of limestone, gypsum and other major raw materials used in Portland cement production. CMAN concluded that, the high cost of Portland cement obey the law of demand and supply [1].

Also, emission of $\mathrm{CO}_{2}$ from cement production is increasing at a much more rapid rate than all other industrial sources put together [2].

The international and national scientific community began to address the economical and environmental problems associated with Portland cement manufacturing sometimes ago; consequently, scientists have been working on a design for new binders for many years and these searches have led 
to the birth of geopolymer among others as an alternative to Portland cement.

Glukhovsky [3] made a significant breakthrough in understanding the principle underlying the production of alkali-activated binders from low calcium clay and alkaline metal solutions which he called these binders or "soil cements" and the respective concretes "soil silicates". Davidovits in 1982 produced binders by mixing alkali solution with thermally activated kaolinite, limestone and dolomite which was termed "geopolymer" because of their polymeric structure [4]. This binder has generated a number of trademarks such as Pyrament, Geopolycem and Geopolymite. Other names have been coined by other authors: hydroceramics (Grutzeck), inorganic polymers (van Deventer) and zeocements (Palomo) [5].

The gradually growing knowledge based on alkali-activated cements and concretes has cast light not only on their benefits in terms of low energy costs and environmental impact, but also their good mechanical performance and long durability, such as Interior of modern aircraft which make use of fire-resistant properties of geopolymer composites $[6,7,8]$.

Olawale has reviewed different materials that could be used for the production of geopolymer and also provided a reaction mechanism of geopolymerisation [2]

The present study was conducted to screen Nigerian kaolinite clay for synthesise of geopolymer binders. The objectives include determination of suitable alkaline environment for the synthesis, evaluation of mechanical and durability properties through compressive strength and water absorption measurements.

\section{Materials}

Kaolin clays from different part of Nigeria were sourced from Federal Institute of Industrial Research Oshodi (FIIRO). The different clays locally named are; Ikere Ekiti (Ekiti State) kaolin, Ikare (Ondo State) kaolin, fired clay (Ozubulu, Imo state), Enugu (Enugu state) kaolin, and laterite (Lagos State). Figure 1 shows the picture of the different kaolinite clays.

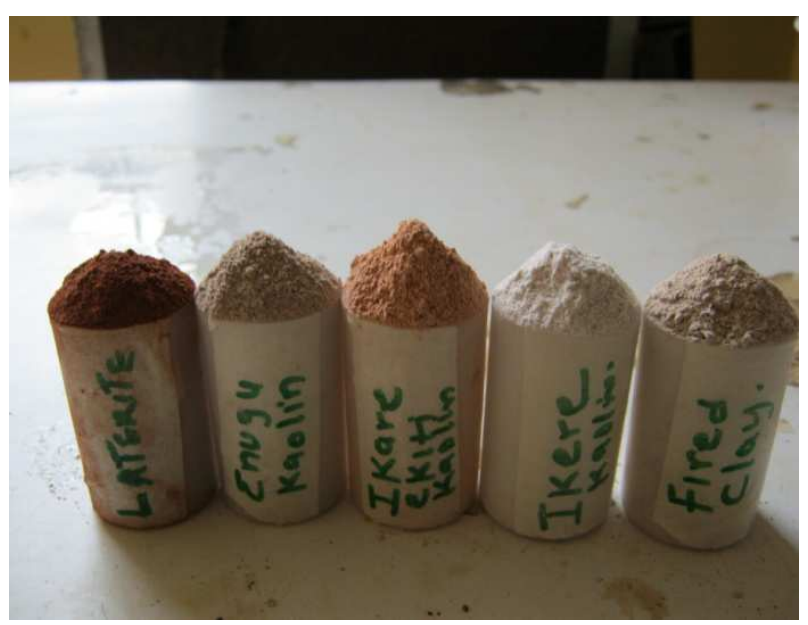

Figure 1. Kaolinite Clays.
- Metakaolins used in the synthesis of geopolymers were obtained by calcining the sourced kaolins at $700^{\circ} \mathrm{C}$ for 5 hours [12].

- Commercial sodium silicate $\left(\mathrm{Na}_{2} \mathrm{O} \%, 23.21 ; \mathrm{SiO}_{2} \%\right.$, 75.36; $\mathrm{Fe}_{2} \mathrm{O}_{3} \%, 0.005 ; \mathrm{TiO}_{2} \%, 0.004 ; \mathrm{Al}_{2} \mathrm{O}_{3} \%, 0.15$, $\mathrm{CaO} \%, 0.032 ; \mathrm{MgO} \%, 0.004$ and $\mathrm{Na}_{2} \mathrm{O} / \mathrm{SiO}_{2}, 2.01$ ) was obtained from Starford Chemicals, Agbara, Ogun State, Nigeria.

- Laboratory grade $\mathrm{NaOH}$ was obtained from Quali Kem chemical industry.

- Freshly distilled water obtained from FIIRO was used throughout the research.

\subsection{Preparation of Geopolymer Binder}

\subsubsection{Preparation of Activators}

Solution of sodium hydroxide pellets of required concentration was prepared 24 hours prior to casting. Sodium silicate solution was used in raw form without any modification. Both solutions were mixed together at the time of casting only when necessary.

\subsubsection{Mix Compositions on Weight Basis}

The ratios of calcined clay: sodium silicate: distilled water was taken as 25.0: 5.0: 5.0 (by weight) for the first batch of geopolymer binder produced. For the second batch of geopolymer, the ratios of calcined clay: sodium silicate: distilled water was taken as 25.0: 5.0: 2.5 (by weight). While the ratio of calcined clay: sodium silicate: sodium hydroxide (by weight) for the third batch of geopolymer binder synthesised was taken to be 25.0: 5.0: 5.0. All batches of geopolymer binders synthesised were cured at four different temperatures.

Geopolymer binders, activated with sodium silicate solution only, were prepared as follows; the predetermined amount of calcined clay was mixed with specific amount of distilled water, and then mixed with predetermined amount of sodium silicate

\subsubsection{Synthesis of Geopolymers}

Geopolymer bricks activated with sodium hydroxide and sodium silicate solutions were prepared as follows; the predetermined amount of sodium hydroxide was dissolved in sodium silicate solution then mixed with calcined clays in a mixer for 5 minutes. Three different batches of geopolymer bricks were synthesised. The first batch of geopolymer bricks synthesised was activated with sodium silicate and water in ratio one to one. The second batch of geopolymer bricks synthesised was activated with sodium silicate and water in ratio one to half. The third batch of geopolymer bricks synthesised was activated with sodium silicate and 14M sodium hydroxide in ratio one to one. The resulting mass of pastes obtained from the mixes were moulded into cylindrical specimens $30.00 \mathrm{~mm}$ in diameter and $40 \mathrm{~mm}$ in height, under a moulding pressure of $15.0 \mathrm{MPa}$ in a special steel mould, using a hand-operating, hydraulic press [9]. First and second batches of geopolymer binder synthesised were cured at room temperature for seven days, $75^{\circ} \mathrm{C}$ for 24 hours, $150^{\circ} \mathrm{C}$ for 24 
hours and $500^{\circ} \mathrm{C}$ for 24 hours. The third batch of geopolymer binder synthesised was cured at $150^{\circ} \mathrm{C}$.

\subsubsection{Curing}

The moulded samples were allowed to mature at room temperature for 24 hours before curing at different temperatures. Curing temperatures are room temperature for 7 days, $75^{\circ} \mathrm{C}$ for 24 hours, $150^{\circ} \mathrm{C}$ for 24 hours, and $500^{\circ} \mathrm{C}$ for 24 hours.

\subsection{Mechanical and Durability Properties}

Compressive strength test was performed on all batches of geopolymer synthesised. Water absorption test was conducted on geopolymers cured at room temperature for 7 days, $75^{\circ} \mathrm{C}$ for 24 hours, $150^{\circ} \mathrm{C}$ for 24 hours and $500^{\circ} \mathrm{C}$ for 24 hours. Compressive strength test and water absorption test were also carried out on geopolymer binder activated with sodium silicate and 14 Molar of sodium hydroxide in ratio one to one.

\subsubsection{Compressive Strength}

Compressive strength of geopolymer was determined by measuring the force (Newton) applied to break the geopolymer binder divided by the area $\left(\mathrm{mm}^{2}\right)$ of the geopolymer. The compressive strength test was performed on two geopolymers [9].

\subsubsection{Water Absorption Test}

The water absorption of the geopolymers was measured after the test specimen has been immersed in water for a defined period and determined as the increase in mass of the test specimen.

\section{(i) Procedure}

Water absorption test[10] was based on NEN-EN 14223.The geopolymers were weighed $\left(\mathrm{M}_{1}\right)$ and then immersed in water for 7 days \pm 4 hours at $(23 \pm 3)^{\circ} \mathrm{C}$. The entire areas of the geopolymers were covered with water during the entire test period. After 7 days of immersion in water, the immersed geopolymer sample was taken out, placed on a flat board and air dried for 5 hours \pm 5 minutes at room temperature. The test samples were reweighed after the drying step $\left(\mathrm{M}_{2}\right)$ [10,13]. Figure 2 shows the picture of geopolymer binders immersed in water.

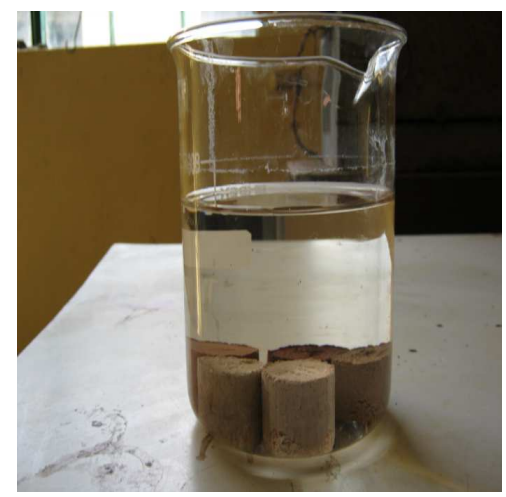

Figure 2. Geopolymer binders immersed in water

\section{(ii) Expression of Results and Calculation}

The water absorption $\mathrm{W}$ for each geopolymer test specimen (expressed as a percentage by mass) was calculated using the equation below.

$$
W \quad=\frac{M_{2}-M_{1}}{M_{1}} \times 100
$$

Where:

$W$ is water absorption of geopolymer test sample expressed as percentage by mass.

$M_{l}$ is the mass of the test specimen after drying.

$M_{2}$ is the mass of the test specimen after immersion in water for 7 days and air-dried for 5 hours $[10,13]$.

\section{Results and Discussion}

\subsection{Compressive Strength}

The results of the average compressive test measured from two cylindrical shaped geopolymer for each set are listed and compared in Figure 3, 4 and 5 below.

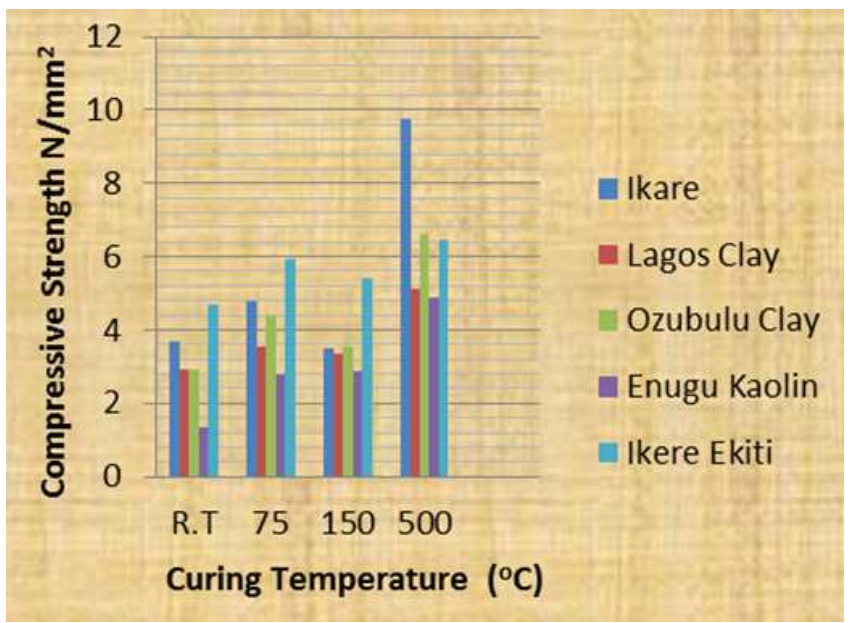

Figure 3. Compressive Strength of Clay Samples Activated with Sodium Silicate and Water in Ratio 1:1.

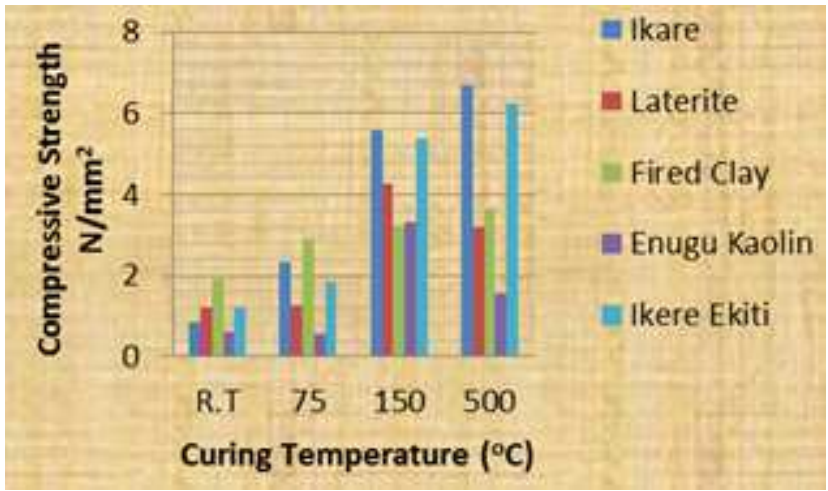

Figure 4. Compressive Strength of Clay Samples Activated With Sodium Silicate and Water in Ratio 1: 0.5 . 


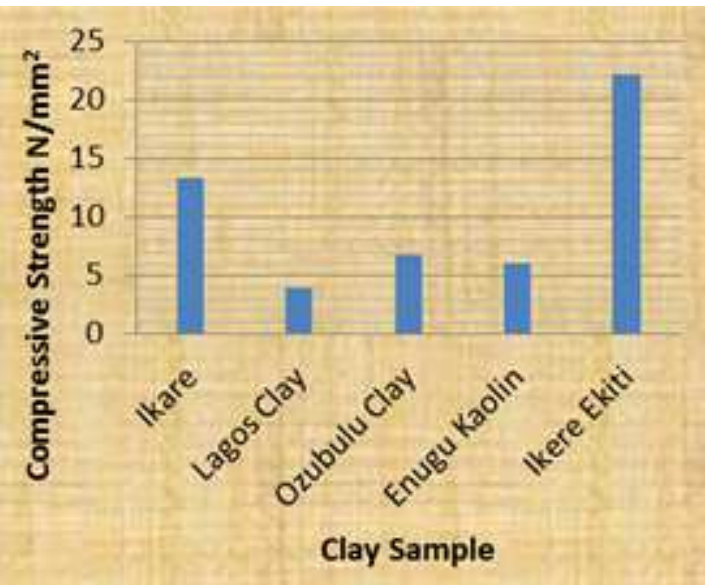

Figure 5. Compressive Strength of Clay Samples Activated with Sodium Silicate and Sodium Hydroxide in Ratio 1:1 and Cured at $150^{\circ} \mathrm{C}$.
The results of compressive strength are presented in Fig. 3 and 4. Compressive strength of geopolymers activated with ratio 1 to 1 activators (sodium silicate and water) is higher than that which was activated with activators at 1 ratio 0.5 . This is likely due to the fact that water plays a significant role in the hydrolysis of the of the silicon and aluminum species of the raw materials. Nigerian clay samples activated with both sodium silicate and $14 \mathrm{M} \mathrm{NaOH}$ in ratio one to one, cured at $150^{\circ} \mathrm{C}$ showed rapid increase in compressive strength (Fig. 5). The sharp increases in compressive strength of these clays was due to addition of sodium hydroxide $(\mathrm{NaOH})$ solution which promote the dissolution and hydrolysis of the soluble aluminosilicate species of the raw materials. $\mathrm{NaOH}$ also raises the rate of strength development as well as largely enhance the final strength by providing more alkaline environment for the geopolmerization.

Table 1. ASTM Specifications for Different Cement Bricks and Load-bearing Concrete Masonry Units (ASTM, C62; C216; C902; C90, 2001).

\begin{tabular}{|c|c|c|c|c|}
\hline Title of Specification & ASTM Designation & Weathering Condition & $\begin{array}{l}\text { Minimum Compressive } \\
\text { Strength (MPa) } \\
\end{array}$ & $\begin{array}{l}\text { Maximum Water Absorption } \\
(\%)\end{array}$ \\
\hline \multirow{3}{*}{ Building Brick } & \multirow{3}{*}{ C62 } & SW & 20.7 & 17 \\
\hline & & MW & 17.2 & 22 \\
\hline & & NW & 10.3 & No limit \\
\hline \multirow{2}{*}{ Facing Brick } & \multirow{2}{*}{$\mathrm{C} 216$} & SW & 20.7 & 17 \\
\hline & & NW & 17.2 & 22 \\
\hline \multirow{2}{*}{ Pedestrian traffic paving brick } & \multirow{2}{*}{ C902 } & MW & 55.2 & 8 \\
\hline & & NW & 20.7 & 14 \\
\hline Loadbearing masonry & C90 & - & 13.1 & 17 \\
\hline
\end{tabular}

SW indicates severe weathering condition, MW indicates moderate weathering condition, and NW indicates negligible or no weathering condition [9].

Comparing the geopolymers activated with both sodium silicate and $14 \mathrm{M} \mathrm{NaOH}$ in ratio one to one with ASTM Specification Standard, Ikare sample satisfied ASTM Specification Standard C62 and C90. Therefore, Ikare can be used for building brick (negligible weathering condition) and load bearing masonry. Also, Ikere Ekiti geopolymer satisfied ASTM Specification Standard C62, C90, C216, and C902. Therefore, Ikere Ekiti can be used for building brick of any weathering conditions, facing brick, load bearing masonry and pedestrian and traffic paving brick except in severe weathering condition.

\subsection{Water Absorption}

Water absorption test performed showed that all the samples have good water absorption capacity at different conditions when compared with ASTM Specification Standard for water absorption, except Enugu kaolin and Ozubulu clay which did not satisfied the ASTM requirements at room temperature and at $75^{\circ} \mathrm{C}$.

Table 2. Water absorption test (percentage by mass).

\begin{tabular}{llllll}
\hline \multirow{2}{*}{ Sample } & \multicolumn{2}{l}{$\mathbf{N a S i}+\mathbf{H}_{2} \mathbf{O}$} & & \multicolumn{2}{c}{$\mathbf{N a S i}+\mathbf{N a O H}$} \\
\cline { 2 - 6 } & $\mathbf{R . T}$ & $\mathbf{7 5}^{\circ} \mathbf{C}$ & $\mathbf{1 5 0}^{\circ} \mathbf{C}$ & $\mathbf{5 0 0}^{\mathbf{0}} \mathbf{C}$ & $\mathbf{1 5 0}^{\mathbf{}} \mathbf{C}$ \\
\hline Ikare & $9.53 \pm 0.50$ & $8.95 \pm 0.65$ & $3.49 \pm 0.02$ & $2.32 \pm 0.34$ & $10.1 \pm 0.09$ \\
Lagos clay & $15.3 \pm 0.18$ & $12.5 \pm 0.02$ & $10.7 \pm 0.29$ & $5.52 \pm 0.02$ & $11.3 \pm 0.85$ \\
Ozubulu Clay & $20.6 \pm 0.72$ & $18.4 \pm 0.18$ & $14.9 \pm 0.08$ & $10.1 \pm 0.26$ & $17.1 \pm 0.03$ \\
Enugu Kaolin & $27.1 \pm 0.01$ & $24.7 \pm 0.18$ & $17.2 \pm 0.35$ & $13.2 \pm 0.27$ & $15.8 \pm 0.37$ \\
Ikere Ekiti & $8.02 \pm 0.05$ & $6.48 \pm 0.26$ & $5.32 \pm 0.25$ & $2.46 \pm 0.26$ & $6.03 \pm 0.15$ \\
\hline
\end{tabular}

\section{Conclusion}

The following conclusions were drawn from the study on
Nigerian clay based geopolymer binder:

Compressive strength increased with increase in curing time from 7 days room temperature to $150^{\circ} \mathrm{C}$.

Comparing the geopolymers activated with both sodium 
silicate and $14 \mathrm{M} \mathrm{NaOH}$ in ratio one to one with ASTM Specification Standard, Ikare sample satisfied ASTM Specification Standard C62 and C90. Therefore, Ikare can be used for building brick (negligible weathering condition) and load bearing masonry.

Also, Ikere Ekiti geopolymer satisfied ASTM Specification Standard C62, C90, C216, and C902. Therefore, Ikere Ekiti can be used for building brick of any weathering conditions, facing brick, load bearing masonry and pedestrian and traffic paving brick except in severe weathering condition.

From water absorption test performed, it can be observed that all the samples have good water absorption property at different conditions when compared with ASTM Specification Standard for water absorption, except Enugu kaolin and fired clay which did not satisfied the ASTM requirements at room temperature and $75^{\circ} \mathrm{C}$.

\section{Acknowledgments}

We appreciate Federal Institute of Industrial Research Oshodi (FIIRO) for providing laboratory support to carry out this research.

\section{References}

[1] Tradeland news (www.tradeland.es)

[2] M. D. Olawale. 2013. Syntheses, Characterization and Binding Strength of Geopolymers: A Review. International Journal of Materials Science and Applications 2(6): 185-193.
[3] V. D. Glukhovsky 1967. Soil Silicate Articles and Structures, Budivelnyk Publisher, Kiev, 156.

[4] J. Davidovits 1984. Synthetic Mineral Polymer Compound of the Silicoaluminates, Family and Preparation.Process, US Patent 4472199.

[5] D. Roy 1999. Alkali-activated cements opportunities and challenges. Cement Concrete Resources 29: 249-54.

[6] R. Sathia, K.G. Babu and M. Santhanam, "Durability study of low calcium fly ash geopolymer concrete", The 3rd ACF International Conference-ACF/VCA, 2008.

[7] T. Bakharev. 2006. Thermal behaviour of geopolymers prepared using class $\mathrm{F}$ fly ash and elevated temperature curing. Cement Concrete Resources 36: 1134-1147.

[8] S. Thokchom, P. Ghosh and S. Ghosh. 2010. Performance of Flyash Based Geopolymer Mortars in Sulphate Solution. Journal of Engineering and Technology Research. 3,1:36-40.

[9] Q. Mohsen and N. Y. Mostafa 2010. Investigating the possibility of utilizing low kaolinitic clays in production of geopolymer bricks. Ceramics - Silikáty 54. 2: 160-168.

[10] Nederlands Normalisatie-instituut (NEN) 2005. Flexible sheets for waterproofing - Waterproofing of concrete bridge decks and other concrete surfaces trafficable by vehicles - Determination of water absorption. ICS 91.100: 50

[11] R. Cioffi, L. Maffucci and L. Santoro. 2003. Optimization of geopolymer synthesis by calcinations and polycondensation of a kaolinitic residue Resources. Conservation and Recycling, 40:27-38. 